\title{
ENSINO DE INGLÊS NA ESCOLA PÚBLICA SOB UMA PERSPECTIVA LUDOSSIGNIFICATIVA UMA PROPOSTA DIDÁTICO-METODOLÓGICA
}

\begin{abstract}
Gabriela Quatrin Marzari é professora do Curso de Letras: Português e Inglês do Centro Universitário Franciscano (UNIFRA/RS) e doutoranda em Estudos Linguísticos na Universidade Católica de Pelotas (UCPel/RS).

E-mail: gabrielamarzari@gmail.com

Gloria Conceição é graduada em Letras: Português e Inglês pelo Centro Universitário Franciscano (UNIFRA/RS) e professora em um curso livre de idiomas.

E-mail: gloria_mconceicao@hotmail.com
\end{abstract}

\section{Resumo}

Este artigo discute o ensino de Inglês na escola pública, considerando as possíveis limitações desse contexto, e apresenta a ludossignificação como uma proposta didático-metodológica alternativa para as aulas de inglês, desenvolvida com base nos estudos neurocientíficos de Kandel (2007), Kupfermann; Schwartz (2000) e Davies (2004).

\begin{abstract}
This article discusses the English teaching in Brazilian public schools, considering the possible limitations of this context, and presents a new didactic-methodological method as an alternative proposal for English classes, which was developed from the neuroscientific studies of memory by kandel (2007), Kupfermann; Schwartz (2000) and Davies (2004).
\end{abstract}

\section{1) Introdução}

A presença da língua inglesa no cenário mundial atual é inquestionável (Paiva, 1996; Rajagopalan, 2005). O inglês se constitui em uma ferramenta necessária à comunicação e à interação efetiva entre os povos. Por isso, não podemos fazer distinções entre quem precisa e quem não precisa aprender esse idioma. De certo modo, todos nós precisamos ou precisaremos dele ao longo de nosso crescimento pessoal ou profissional, em diferentes níveis de exigência, obviamente.

Em função disso, discutiremos nesta pesquisa a importância do papel do professor (Guedes, 2006) ao ensinar inglês na escola pública, por percebermos a importância do idioma atualmente e, considerando as possíveis condições adversas desse contexto, buscar alternativas didático-metodológicas que o auxiliem, bem como aos alunos, durante os processos de ensino e aprendizagem da língua alvo. Sendo assim, também apresentaremos uma proposta didático-metodológica alternativa para ser usada em sala de aula, visando a resultados mais satisfatórios nos processos de ensino e de aprendizagem, a qual foi desenvolvida com base nos estudos neurocientíficos de Kandel (2007), Kupferman e Schwartz (2000), além de outros autores que estudam as conexões cerebrais ou sinapses. 
Ao longo do desenvolvimento das disciplinas de Estágio Supervisionado em Língua Inglesa I e II, ofertadas pelo curso de Letras: Português e Inglês da UNIFRA, as quais previam que o graduando deveria observar aulas de língua inglesa ${ }^{\mathrm{i}}$ ministradas na rede pública de ensino, o estudante de graduação tinha contato direto com os processos de ensino e aprendizagem em um contexto real. Principalmente nas escolas do interior, o aluno estagiário constatava que muitas delas não ofereciam condições favoráveis à aprendizagem, o que torna o trabalho do professor enquanto educador mais difícil, podendo ser decisivo à aprendizagem discente.

Sendo assim, enfatizamos a importância do empenho docente, por considerarmos que muitas escolas públicas não têm verbas suficientes sequer para manter uma infraestrutura adequada, como, por exemplo, salas de aula em bom estado, com mesas e cadeiras escolares, lousas, lâmpadas, latas de lixo, ventiladores, banheiros em bom estado de conservação, entre outros tantos aspectos a serem considerados.

Esperar que escolas públicas com esse perfil ofereçam recursos metodológicos capazes de dar suporte à aprendizagem, como materiais audiovisuais de boa qualidade e em quantidade suficiente, laboratórios de informática devidamente equipados e internet de qualidade para atender a todos os aprendizes, é uma utopia. Por questões como essas, o empenho docente, no que se refere principalmente à metodologia adotada, pode ser decisivo para a aprendizagem dos alunos. Nesse sentido, o professor deve buscar alternativas diversificadas para ensinar a disciplina a que se propõe (Oliveira, 2009).

Levando em consideração a importância do inglês na atualidade e as condições precárias de muitas escolas públicas, durante as disciplinas de Estágio Supervisionado em Língua Inglesa III e IV, também ofertadas pelo curso de Letras da UNIFRA, optamos por uma abordagem diferenciada para o ensino do idioma. Essas disciplinas do curso de Letras preveem que o aluno estagiário ministre aulas em escolas da rede pública para conhecer e se integrar à realidade escolar, já que, em contexto real, é possível mensurar a situação das escolas públicas, desenvolver e aplicar propostas inovadoras em favor da aprendizagem discente.

Sendo assim, a partir da experiência da observação nas disciplinas de estágio, desenvolvidas na graduação em Letras nos semestres anteriores à docência supervisionada, decidimos buscar uma forma de chamar a atenção dos alunos para as aulas de língua inglesa. Optamos por uma proposta didático-metodológica diferenciada, que definimos como ludossignificativa ${ }^{\mathrm{ii}}$, e que apresentaremos com mais detalhes nas seções subsequentes.

Essa maneira de ensinar envolve a ludicidade como um recurso capaz de estimular os sentidos sensório-perceptuais dos alunos, fazendo com que o universo da sala de aula seja mais facilmente memorizado e resgatado em momentos de estudo (Sprenger, 2008). Ainda, o envolvimento do aprendiz com a ludicidade assume um papel importante no que concerne à motivação discente, fazendo com que os alunos participem ativamente das atividades de língua inglesa desenvolvidas em sala de aula e se interessem pela disciplina. Por meio desta pesquisa, pretendemos sensibilizar 
(futuros) professores e demais interessados em metodologias de ensino e aprendizagem de línguas quanto à importância de atividades que envolvem o uso da ludicidade em sala de aula e que, conforme acreditamos, são capazes de estimular os sentidos sensórioperceptuais dos aprendizes.

\section{2) Atividades ludossignificativas como uma possibilidade para o ensino da língua alvo}

Para discutir o papel de atividades ludossignificativas no ensino e na aprendizagem de inglês na escola pública, primeiro definimos o termo mencionado e, a seguir, abordamos dois grandes tópicos: 1) a motivação e suas implicações e 2) a estimulação dos sentidos sensório-perceptuais, sua relação com a memória e a relevância desses estímulos ao longo do processo. Nas próximas subseções, apresentaremos a associação existente entre esses conceitos e as atividades diferenciadas (ludossignificativas) aplicadas em sala de aula, reconhecendo o tipo de estímulo cerebral proposto e o seu papel para a aprendizagem.

Neste estudo, o conceito de ludossignificação está atrelado à relação entre aspectos lúdicos e significação neurológica para o aprendiz. Ou seja, atividades ludossignificativas são aquelas desenvolvidas a partir de estratégias, incluindo a seleção e/ou elaboração dos materiais capazes de estimular os sentidos sensório-perceptuais dos aprendizes, interpretadas pelo cérebro como estímulos significativos, portanto, passíveis de serem recordados posteriormente. Em outras palavras, o evento cerebral criado a partir da estimulação assume uma posição, na memória do indivíduo, que será mais facilmente recuperada em seus momentos de estudo individual ou coletivo, o que caracteriza a ludossignificação.

\section{1) A motivação e suas implicações para o ensino e a aprendizagem}

Sob uma perspectiva neurológica, a motivação é constituída por impulsos relacionados diretamente às necessidades dos indivíduos. De acordo com os neurocientistas Schwartz e Kupfermann (2000), ela norteia impulsos importantes para a (sobre)vivência humana.

Para esses autores, "[o]s estados motivacionais (...) orientam o comportamento para um objetivo especifico, (...) [e] aumentam o estado de alerta geral [energizando] o indivíduo para a ação" (Schwartz; kupfermann, 2000, p. 490). Em outras palavras, a motivação orienta o ser humano para seguir os seus objetivos, focalizando-o em sua busca. Além disso, é capaz de mantê-lo alerta para identificar os indícios de que encontrou o que procurava, provendo-lhe condições para agir em relação aos seus objetivos. 
Esse conceito de motivação pode ser aplicado ao contexto escolar, por exemplo, quando o aluno tem, como objetivo principal, aprender uma língua estrangeira e está alerta para receber os insumos necessários à aprendizagem. Logo após essas duas etapas, ele tem condições de agir, fazendo uso de conhecimentos adquiridos em diferentes contextos.

Em seus estudos sobre o ensino de Inglês como Língua Estrangeira, Harmer (2007) define dois grandes tipos de motivação, que influenciam diretamente a aprendizagem dos alunos: extrinsic motivation e intrinsic motivation. Segundo o autor, a motivação extrínseca (extrinsic motivation) tem origem extraclasse. Ou seja, independentemente dos insumos recebidos em sala de aula, o aluno apresenta alguma motivação para aprender a língua alvo, que pode ser uma exigência familiar, ou a necessidade de saber o idioma no seu ambiente de trabalho, ou simplesmente o gosto pela língua. Já a motivação intrínseca (intrinsic motivation) tem origem dentro da sala de aula e, na maioria das vezes, está vinculada à metodologia de ensino adotada pelo professor.

Dentro da classificação intitulada motivação intrínseca, Harmer (2007) destaca alguns tipos de ocorrência. Neste estudo, mencionaremos apenas dois deles. O primeiro está relacionado à metodologia adotada pelo professor. Seguindo essa concepção, o professor cria, em sala de aula, uma atmosfera favorável à aprendizagem, por exemplo, a partir de atividades que estimulem os sentidos sensório-perceptuais dos alunos, capazes de chamar a sua atenção para os conteúdos que serão abordados.

O segundo tipo de motivação intrínseca, conforme proposto por Harmer (2007), está ligado à percepção do aluno em relação ao seu êxito ou insucesso quanto à aprendizagem de inglês. Em outras palavras, se o aprendiz tiver ao menos a impressão de estar aprendendo a língua alvo, ele se sentirá motivado a aprendê-la cada vez mais, pois a sensação de vitória estimula os neurônios VTA, os quais estão envolvidos na motivação por serem suscetíveis à dopamina (Schwartz; Kupfermann, 2000), substância que provoca a sensação de prazer (Sprenger, 2008).

Quando o professor utiliza materiais didáticos capazes de estimular os sentidos sensório-perceptuais dos alunos, as informações são mais facilmente armazenadas e resgatadas pelo cérebro quando necessário. Esse resgate mnemônico causa nos alunos a percepção ou impressão de aprendizagem, o que caracteriza a motivação intrínseca de segundo tipo, e leva o aluno a, cada vez mais, querer obter a sensação de sucesso.

A motivação, seja ela intrínseca ou extrínseca, impulsiona o aluno a participar da aula, fazendo com que ele se exponha a diferentes estímulos capazes de aguçar habilidades linguísticas específicas e, possivelmente, concretizar a aprendizagem. Quando o aluno é/está motivado a aprender, ele apresenta uma predisposição a participar das atividades propostas, o que provavelmente resultará em internalização e gerenciamento dos conteúdos a que foi exposto.

Para Guedes (2006), o professor ideal é aquele capaz de criar um ambiente que promova a aprendizagem discente, exercendo o trabalho de mediador entre os conteúdos 
a serem desenvolvidos, por meio de diversas atividades, e seus aprendizes. Portanto, caberá ao professor criar uma atmosfera favorável à aprendizagem para que seus alunos se sintam motivados a aprender e acabem assimilando estruturas, usos e significados da língua alvo.

\section{2) A importância da memória e dos sentidos sensório-perceptuais para a aprendizagem}

A memória é uma grande aliada da aprendizagem de idiomas por influenciar a escolha das estratégias utilizadas ao longo do processo (Davies, 2004). Existem dois grandes tipos de memória: a de curto prazo e a de longo prazo, sendo a última subdividida em implícita e explícita (Kupffermann; Kandel, 2000). Kandel (2007) afirma que, por um determinado período de tempo, minutos, dias ou semanas, as informações localizam-se no hipocampo, uma região relativamente pequena do interior do nosso cérebro. Com o passar do tempo, essas informações migram para as demais regiões do cérebro, como o córtex, para sofrer processos de armazenamento permanente.

A memória de curto prazo é um processo cerebral transitório, que resgata as informações armazenadas no hipocampo (Kandel, 2000). Para exemplificar a memória de curto prazo, Davies (2004) apresenta como exemplo a necessidade de lembrarmos de um número telefônico. Essa memória poderá ser transformada em memória de longo prazo se o indivíduo interessado nessa informação despender atenção e prática em certos exercícios mnemônicos que farão com que essa informação, gradativamente, mude de lugar no cérebro e se aloje na região que provavelmente seja destinada à memória de longo prazo, o córtex, de acordo com Kandel (2007).

O segundo tipo de memória é a de longo prazo, que é estável por estar internalizada no cérebro e poder ser acessada pelo indivíduo quando necessário, consciente ou inconscientemente (Kupfermann; Kandel, 2000). A memória permanente implícita tem características automáticas e reflexivas. Em outras palavras, sua formação e resgate não estão necessariamente relacionados ao estado de consciência do indivíduo. Kupfermann e Kandel (2000) destacam, como exemplo desse tipo de memória, a aquisição de certas regras como a gramática universal, conforme definida pelo linguista Chomsky, em 1957, e de atividades automaticamente internalizadas, como dirigir um carro ou caminhar.

Já a memória permanente explícita refere-se ao resgate mental consciente de eventos autobiográficos ou históricos (Kupfermann; Kandel, 2000), ou seja, em algum momento da vida, as pessoas necessitam lembrar certas informações e, então, as resgatam. Os autores supracitados afirmam que esse tipo de memória acontece em avaliações formais ou está relacionado a experiências únicas, estas lembradas através de frases declarativas concisas como: "No último verão, visitei minha avó em sua casa de campo.” (Kupfermann; Kandel, 2000, p. 522). 
Com relação aos registros mentais que fazemos, Kandel (2007) afirma que os estímulos captados pelo cérebro são capazes de alterar a expressão dos genes cerebrais e é por essa razão, segundo o autor, que nos lembramos das informações. Ou seja, cada vez que aprendemos, nosso hipocampo é alterado para que as novas informações sejam registradas e armazenadas. Posteriormente, essas informações podem ser resgatadas e, em casos específicos, enviadas para as demais regiões do cérebro para seu armazenamento na memória de longo prazo.

No que diz respeito à captação cerebral das informações, Kandel (2007) afirma que os estímulos captados pelos sentidos sensório-perceptuais causam alguma interferência em determinada região do hipocampo. Em outras palavras, quando somos estimulados através dos nossos sentidos sensório-perceptuais, nossa memória automaticamente registra as informações sobressalentes.

Buzan (2009) destaca que pesquisas envolvendo os mecanismos de memorização têm revelado que o nosso cérebro responde melhor a determinados estímulos. $\mathrm{O}$ autor apresenta diferentes maneiras capazes de incitar o cérebro a se recordar de certas informações. Para esta pesquisa, destacamos duas delas, as quais consideramos mais viáveis de serem relacionadas à ludicidade e à aprendizagem em sala de aula.

Para o autor, então, uma das maneiras de incitarmos o cérebro é através dos nossos sentidos: a visão, a audição, o tato, o olfato, o paladar ou o sentido cinestésico, que trata da consciência que temos de nossa posição corporal e do movimento no espaço; e a outra, através de associações, as quais permitem estimular a memória a lembrar de eventos com mais facilidade. No entanto, a ênfase desta pesquisa está nas maneiras de que dispomos para estimular os sentidos, pois as associações são possíveis somente através deles.

No que concerne aos seis sentidos e à sala de aula, é mais comum estimularmos a visão e a audição dos alunos, para que se lembrem posteriormente do que viram ou ouviram em aula. Além disso, é possível estimularmos os demais sentidos, como o cinestésico e o tato, por meio de atividades diversificadas. No entanto, o olfato e o paladar são os sentidos mais difíceis de serem estimulados em aula em prol da aprendizagem, devido às condições oferecidas pelo contexto escolar. Segundo Davies (2004), existem alguns estímulos que podem influenciar os nossos sentidos e, dentre eles, seleciono cinco: o movimento, o humor, a cor, a ordem/sequência, a positividade e o exagero.

Para esse autor, o movimento que os corpos podem exercer no espaço possibilita mais opções de conexões cerebrais; já com relação ao humor, quanto mais irreverente é uma imagem, mais facilmente ela é lembrada, o que pode também ser relacionado com a positividade, pois, segundo Davies (2004), o cérebro tende a lembrar com mais facilidade daquilo que foi positivo ou prazeroso para o indivíduo. Ainda, o cérebro responde melhor a estímulos exagerados (tamanho, forma, volume ou movimento), o 
que também pode ser associado com a cor, visto que, de acordo com o autor, lembramos com mais facilidade de cores fortes e imagens com variações de cor.

Com relação às associações, Davies (2004) afirma que, quando somos capazes de associar uma informação nova a um conhecimento já internalizado, nosso cérebro registra mais facilmente a informação nova, por resgatar o que já sabemos sobre assunto tratado, ponderando a relevância da informação nova em relação à(s) antiga(s). Sprenger (2008, p. 24) também faz considerações a esse respeito, ao afirmar que "(...) o hipocampo tem um papel importante no processo da atenção. Devido ao acesso a tantas memórias, se o sistema de ativação reticular reage a alguma estimulação sensorial, o hipocampo pode compará-lo a antigas experiências e determinar sua novidade."

Logo, Sprenger (2008) considera que as informações novas podem ser associadas pelo nosso cérebro aos conhecimentos já internalizados, e isso acontece graças ao nosso hipocampo cerebral, que é capaz de avaliar a nova informação ao identificar o conhecimento a ela relacionado.

Davies (2004) destaca ainda que os estudos em Programação Neuro-Linguística (PNL) apresentam certas observações quanto ao processo de aprendizagem. Destacamos duas dessas observações, as quais consideramos bastante pertinentes para esta pesquisa:

$1^{\text {a) }}$ cada pessoa tem uma maneira diferente de aprender, pois temos visões de mundo e interesses distintos. Portanto, cada um de nós é mais estimulado a partir de um ou mais sentidos específicos;

$2^{\mathrm{a}}$ ) nós aprendemos com mais facilidade quando estamos em uma atmosfera lúdica. Ou seja, já que o nosso cérebro está predisposto a armazenar eventos prazerosos, armazenamos as informações mais facilmente quando aprendemos nos divertindo. Os estímulos definidos como positividade e humor estão diretamente relacionados a essa ideia, pois estão presentes em momentos de descontração, como é o caso das brincadeiras lúdicas, ou em atividades didático-pedagógicas que proporcionam momentos de ludicidade.

Sendo assim, a partir dos dados apresentados, acreditamos que atividades diferenciadas, que se baseiam em estímulos como movimento, humor, cor, ordem/sequência, positividade e exagero são mais facilmente captadas por nossos sentidos sensório-perceptuais, possibilitando associações com os conhecimentos já internalizados pelo aprendiz. Portanto, as informações advindas dessas práticas ludossignificativas são mais facilmente armazenadas na memória, visto que registramos no cérebro as informações sobressalentes. Logo, quanto mais estímulos, mais informações armazenaremos na memória.

Vale lembrar ainda que, considerando que cada pessoa tem uma maneira diferente de se identificar com as informações que recebe (Davies, 2004), o professor deve apresentar aos alunos diferentes propostas de estímulo, por considerar a heterogeneidade existente em sala de aula. Em outras palavras, nem todos os aprendizes estarão igualmente suscetíveis ao mesmo estímulo proposto. Por isso, variar as técnicas 
em sala de aula é uma maneira de possibilitar que mais e mais alunos sejam "atingidos" durante o processo de aprendizagem.

\section{3) Atividades didático-metodológicas: descrição e análise sob uma perspectiva ludossignificativa}

Descreveremos, a seguir, duas atividades que envolvem aspectos lúdicos, desenvolvidas nas disciplinas de Estágio Supervisionado em Língua Inglesa III e IV. Cabe destacar que todos os conteúdos abordados ao longo dos estágios estavam previstos no programa da disciplina de Língua Inglesa das escolas onde as atividades de estágio foram desenvolvidas, que, por sua vez, fundamenta-se nos PCN.

\section{1) Momentos de atividade em aula: engage, study e activate}

Para desenvolvermos esta subseção, partimos do conceito de atividade, aqui entendida como a proposta apresentada aos alunos. Além disso, entendemos que as atividades podem identificar os diferentes momentos da aula, definidos como engage, study e activate, conforme propostos por Harmer (2007) para a construção do conhecimento em ambiente escolar, os quais são trabalhados alternadamente de acordo com o nível da turma e a sua necessidade.

Para esse autor, engage é o momento em que o professor chama a atenção da turma para o que pretende apresentar; pode acontecer através de perguntas sobre a vida dos alunos, ou o que eles pensam sobre determinado tema. O momento study ocorre quando o aluno trabalha com a língua; suas estruturas, usos e porquês; nesse momento, então, o estudo da língua é o foco principal. Já no último momento apresentado por Harmer (2007), activate, o aluno desenvolve as diferentes habilidades, praticando a língua de acordo com os conhecimentos já internalizados, ou em fase de internalização, sem ter consciência plena do uso de regras.

A seguir apresentamos duas atividades embasadas no momento study, uma destinada ao Ensino Fundamental e outra, ao Ensino Médio. Durante as práticas de estágio, as atividades permearam apenas os momentos engage e study, pois o terceiro momento, activate, só é possível de ser atingido quando os alunos já possuem conhecimento intermediário da língua inglesa, o que, no momento da pesquisa, não foi constatado.

\section{2) O momento study a serviço da aquisição de vocabulário no Ensino Fundamental}

A aquisição de vocabulário pode ser considerada uma atividade de study, com base nas definições apresentadas por Harmer (2007), pois os alunos estão trabalhando a língua alvo de forma consciente nesta etapa do processo. Para desenvolver uma 
atividade de aquisição de vocabulário referente ao campo semântico "frutas", na turma de Ensino Fundamental, selecionamos sete frutas de plástico, adquiridas por cerca de dois reais cada, em uma loja de utensílios e enfeites de cozinha. As frutas escolhidas foram: apple, banana, grapes, papaya, peach, orange e watermelon. Feito isso, selecionamos números de 1 a 7 , confeccionados em material EVA, contendo cerca de 15 centímetros de comprimento cada.

Já na sala de aula, antes de apresentar as frutas aos alunos, mostramos a eles os números e pedimos que os dissessem em inglês, a fim de que apenas ativassem esse conhecimento já internalizado. Apresentamos a seguir uma foto ilustrativa dos números utilizados em aula:

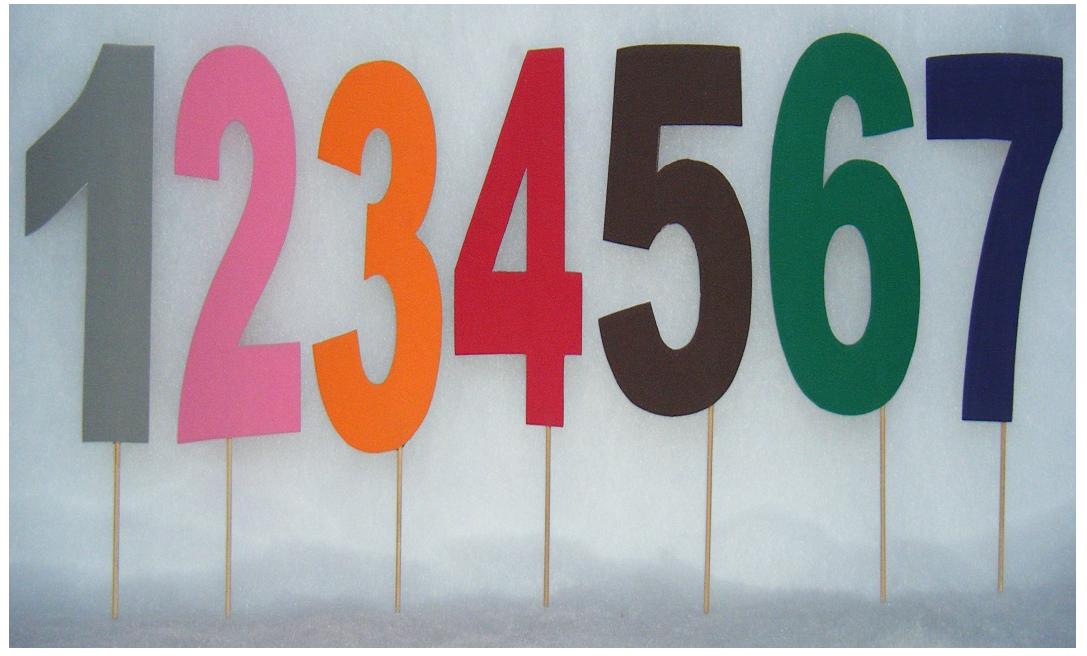

Figura 1: Números

Em seguida, comunicamos aos alunos que faríamos um exercício de memorização tendo em vista a aquisição de vocabulário. Sendo assim, eles deveriam prestar atenção na proposta e testar a memória. Mostramos o número 1 e pegamos a fruta de nome apple. Pronunciamos a palavra em voz alta, escrevemos a palavra no quadro em letras garrafais e, em seguida, pedimos que toda a turma repetisse, em voz alta, o termo apple.

Depois, mostramos o número 2, pegamos a fruta de nome banana, repetimos a palavra, escrevemos a palavra banana abaixo da palavra apple na lousa e solicitamos à turma que repetisse, em voz alta, o termo banana. Seguimos o mesmo procedimento com as demais frutas selecionadas, e as organizamos em sequência, da esquerda para a direita, sobre a mesa do professor ao longo do desenvolvimento da atividade. Apresentamos, a seguir, algumas das frutas utilizadas na atividade acima descrita: 


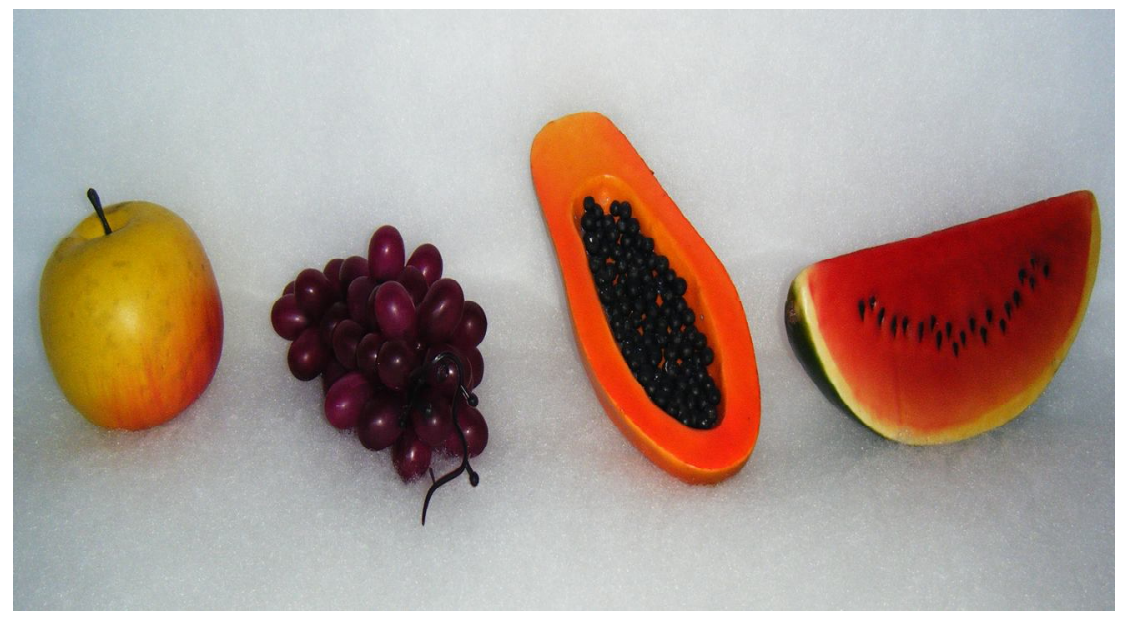

Figura 2: Frutas de plástico

Depois disso, relembramos aos alunos o significado da frase "where is the...?" e, em seguida, solicitamos a eles que pegassem determinada fruta assim que alguém - a professora ou um dos colegas - fizesse a pergunta "Where is the apple?", por exemplo, sempre variando o nome da fruta a cada nova pergunta. Prontamente os alunos levantavam-se, dirigiam-se até a mesa e selecionavam a fruta certa. Mesmo que eles ainda não soubessem o nome da fruta, por lógica, conseguiam deduzir qual era, pois percebiam que nós as tínhamos organizado em sequência sobre a mesa e, além disso, escrito seus nomes, também em sequência, na lousa.

Durante essa atividade, a ludossignificação se caracteriza pelos seguintes estímulos propostos por Davies (2004): sequência, considerando-se os números e a organização das frutas em ordem alfabética; movimento, já que as frutas e os números utilizados são objetos tridimensionais, palpáveis e possíveis de serem deslocados de um lugar para outro; cor, considerando-se que os números e as frutas utilizados são de cores variadas; positividade, pelo fato de que todos os estímulos acima, utilizados como estratégia para a memorização do vocabulário, configuram um ambiente lúdico de descontração, sendo, portanto, encarado como positivo pelo nosso cérebro.

Ainda, essa atividade envolveu processos associativos (Davies, 2004), uma vez que os alunos já conheciam as frutas e sabiam seus nomes em português. Sendo assim, depois da atividade proposta, também ficaram conhecendo seus nomes em língua inglesa, ou os lembraram de maneira ludossignificativa, a partir dos estímulos a que foram expostos.

Os sentidos estimulados nessa atividade foram a visão, através dos números em EVA e das frutas palpáveis (cor, movimento, sequência e positividade), e a audição, através da repetição. Outros sentidos trabalhados com alguns alunos foram o cinestésico e o tato, quando estes se dispuseram a levantar de suas cadeiras e ir até a mesa da professora para tocar a fruta com as mãos, interagindo com o espaço em que estavam.

Cabe ainda mencionar que todas as estratégias de estímulo utilizadas, de certa forma, despertaram o interesse da maioria dos alunos para participar da atividade 
proposta, o que caracteriza a motivação intrínseca, proposta por Harmer (2007), de ambos os tipos, uma vez que a metodologia adotada despertou o interesse dos alunos, que se motivaram a prestar atenção na atividade e a participar dela. Ao participarem da atividade e conseguirem desenvolvê-la com êxito, acertando os nomes das frutas, os alunos se sentiram cada vez mais motivados a participar da atividade proposta.

\section{3) Momento study: a estrutura das frases em língua inglesa através das "caixas sintáticas" no Ensino Médio}

Durante o momento study, uma das atividades que mais teve resultados positivos foi o uso das "caixas sintáticas", desenvolvidas como instrumento didáticometodológico a ser utilizado em um período de tempo superior a 50 minutos. Esse material, desenvolvido a partir de caixas contendo cerca de 25 centímetros de comprimento, 20 de altura e 5 de espessura, revestidas com pedaços de papel jornal, foi utilizado para mostrar aos alunos as estruturas afirmativa, interrogativa e negativa do verbo there to be.

Para poder explicar essas estruturas através das "caixas sintáticas", confeccionamos algumas palavras (there, is, are, a, car, cars, here, not) e os sinais gráficos ponto final e interrogação com material EVA colorido. Em seguida, fixamos as palavras e os sinais gráficos de pontuação em sete caixas, aproveitando, muitas vezes, ambos os lados de cada caixa, de modo que fosse possível formar sentenças como: "There is (not) a car here" e "There are (not) cars here". Como ilustração desse material, apresentamos a Figura 3, conforme segue:

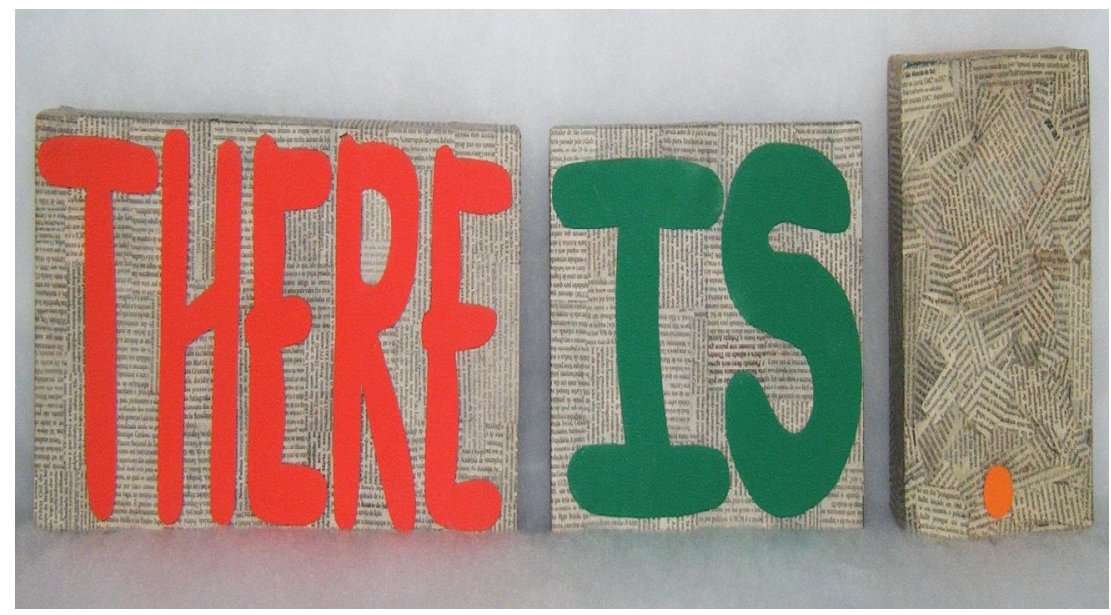

Figura 3: Amostra das "caixas sintáticas"

A fim de mostrarmos aos alunos a estrutura da frase interrogativa, dispusemos, sobre a mesa da professora, as cinco caixas, de modo que fosse possível ler, primeiramente, a sentença "There is a car here." Feito isso, mostramos aos alunos a estrutura da pergunta, deslocando a caixa is para frente de todas as demais, mudando o 
símbolo gráfico de ponto final para interrogação, conforme esclarece a ilustração abaixo, e alterando a entonação ao proferi-la:

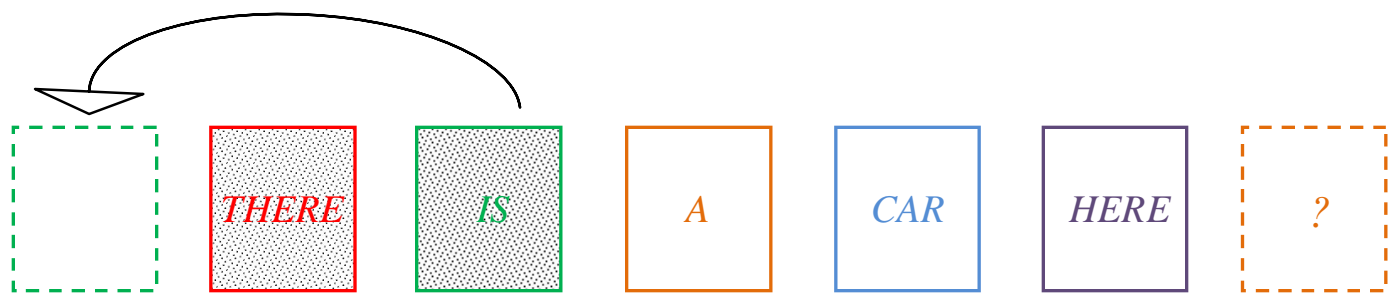

Figura 4: Disposição das caixas sintáticas

Realizamos o mesmo procedimento com a sentença no plural There are cars here, procurando contextualizá-la com o estacionamento da escola. Depois de já compreenderem o uso do singular e do plural do verbo there to be e as estruturas afirmativa e interrogativa, fizemos algumas perguntas aos alunos relacionadas à sala de aula, utilizando o vocabulário previamente trabalhado, encontrado nesse contexto, como book, pen, chair, blackboard, chalk, dentre outros, enfatizando a pronúncia nos grupos is there e are there, para que identificassem se a frase estava no singular ou no plural. Pudemos, ainda, associar esse conteúdo aos demais que já haviam sido estudados, como as preposições espaciais in, on, under, behind, beside, between e os pronomes demonstrativos this e that, por exemplo, através da pergunta "Is there a pen behind that book?" e do gesto de apontar para o livro a que nos referíamos. Os alunos respondiam às perguntas oralmente, pois podiam olhar para as caixas, caso esquecessem a estrutura previamente ilustrada.

Para chamar a atenção dos alunos sobre a estrutura negativa, perguntamos "IS there a dog here?", enfatizando, nesse caso, a palavra dog. Alguns alunos responderam "No", seguido de uma pausa, por não terem certeza da estrutura gramatical correta, necessária à resposta; outros, contudo, responderam "No, there is", pois muitos deles ainda não conheciam a estrutura negativa do verbo there to be.

A partir da resposta gramaticalmente incorreta, explicamos a estrutura da frase negativa, explicitando-a através das caixas. Em seguida, fizemos mais perguntas, misturando todos os tipos de pergunta e corrigindo os equívocos oralmente, na hora em que eram cometidos (feedback imediato), e solicitando que eles repetissem a frase gramaticalmente correta.

Essa atividade ludossignificativa envolveu, basicamente, os estímulos exagero, cor, movimento e positividade (Davies, 2004), captados através da visão e da audição. O exagero esteve presente em toda a atividade, visto que a sala de aula ficou cheia de materiais que regularmente não fazem parte desse contexto. Além disso, a pronúncia das sentenças, com ênfase em palavras específicas, também caracterizou o exagero, captado pela audição. A cor esteve presente nas palavras fixadas nas caixas, o que configurou um estímulo de ordem visual. Já a positividade apareceu porque os demais estímulos criaram um ambiente de ludicidade e, em momentos como esse, nosso cérebro tende a 
registrar as informações com mais facilidade. Além disso, ao responderem às perguntas corretamente, os alunos eram elogiados e, por isso, sentiam-se motivados, caracterizando, assim, um momento positivo no processo de aprendizagem. $\mathrm{O}$ movimento, captado pela visão, esteve relacionado à tridimensionalidade das caixas e, também, à mudança de posição de algumas delas, principalmente, das caixas $I S$ e $A R E$, para formar as diferentes estruturas gramaticais.

Com relação à motivação (Harmer, 2007), constatamos a presença da intrínseca dos dois tipos, conforme abordados anteriormente nesta pesquisa. O material didático utilizado foi capaz de despertar o interesse da maioria dos alunos para a atividade e de prender a atenção da turma de um modo geral, caracterizando o primeiro tipo de motivação intrínseca. Já o segundo tipo ocorreu quando os alunos perceberam que formular as frases em inglês era uma atividade relativamente fácil, visto que as caixas os ajudaram a ilustrar os exemplos. Sendo assim, quanto mais eles desenvolviam a habilidade oral em língua inglesa, mais queriam participar da atividade proposta.

\section{4) Considerações finais}

O contexto educacional público brasileiro desafia, constantemente, os profissionais da educação pelo fato de, muitas vezes, oferecer poucos recursos tecnológicos e de infraestrutura, o que acaba limitando o trabalho do professor, que não encontra opções didático-metodológicas para serem utilizadas no contexto escolar, além dos tradicionais giz e lousa. No entanto, conforme argumenta Guedes (2006), os professores devem estar em constante atualização, sempre buscando diferentes maneiras de desenvolver os conteúdos do programa de cada série do ensino regular, para atingirem o que se define por perfil ideal do professor, em favor da aprendizagem discente.

As atividades ludossignificativas são uma alternativa para chamar a atenção dos alunos para os conteúdos gramaticais e para motivá-los a aprender, principalmente quando não encontramos na escola aparelhos audiovisuais capazes de estimular o cérebro naturalmente. Então, a ludossignificação é um passo primário para o ensino de inglês, mas não deve ser considerado o único, pois não podemos dissociar os aprendizes de língua inglesa dos questionamentos acerca da cultura estrangeira e da realidade social.

Para finalizar, cabe destacar que pesquisas desta natureza são essenciais ao aprimoramento da prática docente em escolas de Ensino Fundamental e Médio da rede pública. Este estudo representa o início de uma proposta de discussão bastante profícua na área da educação, particularmente no ensino de línguas, sobretudo estrangeiras. Esta 
pesquisa privilegiou o ensino de inglês a partir de estímulos capazes de exercitar as conexões cerebrais, facilitando a memorização e o resgate das informações. No entanto, outros aspectos podem ser considerados em pesquisas futuras, visto que o cérebro humano e a aquisição da linguagem permitem inúmeras possibilidades de investigação e análise.

\footnotetext{
${ }^{\mathrm{i}}$ Ao longo deste trabalho, língua inglesa (iniciais minúsculas) refere-se ao idioma. Já Língua Inglesa (iniciais maiúsculas), à disciplina.

ii $\mathrm{O}$ substantivo ludossignificação e seus derivados foram cunhados por nós, a fim de sintetizar a ideia básica da metodologia desenvolvida ao longo das práticas de Estágio Supervisionado em Língua Inglesa III e IV.
}

\section{Referências bibliográficas}

BUZAN, Tony. Memória brilhante. Tradução de Antônio Moura. Rio de Janeiro: Sextante, 2009.

CHOMSKY, Noam. Linguagem e mente. Tradução de Lúcia Lobato. Brasília: Universidade de Brasília, 1998.

DAVIES, Ben Perry. Inglês que não falha: técnicas e exercícios de memorização. Rio de Janeiro: Elsevier, 2004.

GUEDES, Paulo. A formação do professor de português: que língua vamos ensinar?. São Paulo: DP\&A, 2006.

HARMER, Jeremy. How to teach English: an introduction to the practice of English language teaching. Cambridge: Longman, 2007.

KANDEL, Eric R. In search of memory: the emergence of a new science of mind. New York: WW Norton, 2007.

KUPFERMAN, Irving.; KANDEL, Eric. Aprendizado e memória. In: JESSEL, Thomas M.; SCHWARTZ, James H.; KANDEL, Eric, R. Fundamentos da neurociência e do comportamento. Rio de Janeiro: Guanabara Koogan, 2000. p. 519-530.

KUPFERMAN, Irving.; SCHWARTZ, James. Motivação. In: JESSEL, Thomas M.; SCHWARTZ, James H.; KANDEL, Eric, R. Fundamentos da neurociência e do comportamento. Rio de Janeiro: Guanabara Koogan, 2000. p. 489-500. 
OLIVEIRA, Adelaide P. de. Abordagens alternativas no ensino de inglês. In: Diógenes Cândido de (Org.). Ensino e aprendizagem de língua inglesa: conversas com especialistas. São Paulo: Parábola Editorial, 2009. p. 141-149.

PAIVA, Vera Lúcia Menezes de Oliveira. A língua inglesa no Brasil e no mundo. In: PAIVA, Vera Lúcia Menezes de Oliveira (Org.). Ensino de Língua Inglesa, reflexões e experiências. São Paulo: Pontes, 1996. p. 9-29.

RAJAGOPALAN, Kanavillil. A geopolítica da língua inglesa e seus reflexos no Brasil. In: RAJAGOPALAN, Kanavillil; LACOSTE, Yves (Orgs.). A geopolítica do Inglês. São Paulo: Parábola Editorial, 2005, p. 135-159.

SPRENGER, Marilee. Memória: como ensinar para o aluno lembrar. Tradução de Magda França Lopes. Porto Alegre: Artmed, 2008. 